\title{
Inhibitory influence of natural flavonoids on human protein kinase CK2 isoforms: effect of the regulatory subunit
}

\author{
Andrea Baier $^{1}$ (D) Jolanta Nazaruk ${ }^{2} \cdot$ Anna Galicka $^{3} \cdot$ Ryszard Szyszka $^{1}$
}

Received: 11 July 2017 / Accepted: 24 November 2017 / Published online: 29 November 2017

(C) The Author(s) 2017. This article is an open access publication

\begin{abstract}
CK2 is a pleiotropic, constitutively active protein kinase responsible for the phosphorylation of more than 300 physiological substrates. Typically, this enzyme is found in tetrameric form consisting of two regulatory subunits CK2 $\beta$ and two catalytic subunits CK $2 \alpha$ or CK $2 \alpha^{\prime}$. Several natural occurring flavonoids were tested for their ability to inhibit both CK2 holoenzymes, CK $2 \alpha_{2} \beta_{2}$ and CK $2 \alpha_{2}^{\prime} \beta_{2}$. We identified few substances selectively inhibiting only the $\alpha^{\prime}$ subunit. Other compounds showed similar effect towards all four isoforms. In some cases, like chrysoeriol, pedalitin, apigenin, and luteolin, the $\alpha_{2} \beta_{2}$ holoenzyme was at least six times better inhibited than the free $\alpha$ subunit. Otherwise, we have found a luteolin derivative decreased the kinase activity of CK2 $\alpha^{\prime}$ with an $\mathrm{IC}_{50}$ value of $0.8 \mu \mathrm{M}$, but the holoenzyme only with $9.5 \mu \mathrm{M}$.
\end{abstract}

Keywords CK2 holoenzymes $\cdot$ Flavonoids $\cdot$ Phosphorylation $\cdot$ Inhibitors

\section{Introduction}

Protein kinase CK2 is a highly conserved serine/threonine kinase considered as constitutively active and ubiquitously expressed. CK2 is known to play an essential role in cellular processes, e.g., cell proliferation, cell growth, and cell survival, cell morphology, and promotes angiogenesis [1-9]. In many reports, the implication of CK2 in several pathologies is described, like neurodegenerative diseases (Parkinson's and Alzheimer's disease), inflammation, virus and parasite infections, and cancer [10].

CK2 can function as monomeric kinases, but also as tetrameric complexes. In human, the monomeric forms are designated as CK2 $\alpha$ and CK2 $\alpha^{\prime}$, being the catalytic subunits of CK2. The tetrameric isoforms consist of two catalytic subunits each bound to a regulatory subunit CK2 $\beta$ whereas two of them form a dimer. Within the CK2 holoenzyme,

Andrea Baier

baier@kul.pl

1 Department of Molecular Biology, The John Paul II Catholic University of Lublin, ul. Konstantynow 1i, 20-708 Lublin, Poland

2 Department of Pharmacognosy, Medical University of Białystok, ul. Mickiewicza 2a, 15-089 Białystok, Poland

3 Department of Medical Chemistry, Medical University of Białystok, ul. Mickiewicza 2a, 15-089 Białystok, Poland the regulatory CK2 subunit alters substrate specificity [11]. Calmodulin is only phosphorylated by the free catalytic subunits, while eIF2 $\beta$ is phosphorylated after reconstitution of the CK2 holoenzyme $[12,13]$. The mechanism by which the regulatory subunit is able to regulate the activity of the catalytic subunit is still not clarified.

Both catalytic subunits possess very similar $\mathrm{N}$-terminal amino acid sequences, whereas they differ at the C-terminal part. Characteristic features are the ATP-binding motif $\left(\mathrm{G}^{46} \mathrm{XGXXS}^{51}\right)$, the catalytic loop (residues $\mathrm{R}^{155}, \mathrm{D}^{156}$ and $\mathrm{H}^{160}$ ), the activation loop (sequences $\mathrm{D}^{175} \mathrm{WG}^{177}$ and $\mathrm{G}^{199} \mathrm{PE}^{201}$ ), and the substrate binding site (residues $\mathrm{R}^{191}$, $\mathrm{R}^{195}, \mathrm{~K}^{198}$, and $\left.\mathrm{K}^{74}-\mathrm{R}^{80}\right)[14,15]$.

Beside these structural similarities distinct functional properties have been reported for both isoforms. As shown in mice, CK $2 \alpha$ is expressed ubiquitously in all tissues, whereas CK2 $\alpha^{\prime}$ is detected exclusively in the brain and in the testes [16]. Furthermore, knockout experiments in mice suggest discrete functions for these isoforms. Mice with knockout of the gene encoding for CK2 $\alpha$ subunit are non-viable. Otherwise, mice lacking the CK2 $\alpha^{\prime}$ subunit develop normally and survive into adulthood but males are infertile [17].

Since more than two decades research groups are in the search for potent and selective CK2 inhibitors. Those substances may act on several targets, like the ATP-binding site, the protein substrate-binding site, allosterically hindering substrate or co-substrate binding and inhibition of 
holoenzyme assembly [18]. The list of classes of compounds effectively inhibiting the CK2 activity is still growing, e.g., halogenated $\mathrm{lH}$-benzimidazole derivatives, anthraquinones, coumarins, flavonoid derivatives, indeno[1,2-b]indole derivatives, pyrazolo-triazines, and carboxyl acid derivatives [19-25].

Recently, there has been an upsurge of interest in the therapeutic potential of medicinal plants which might be due to their phenolic compounds, specifically to flavonoids [26, 27]. They are most common and widely distributed group of compounds in plants, found in almost all plant parts, especially in photosynthesizing plant cells. They can be divided into a variety of classes such as flavones (e.g., flavone, apigenin, and luteolin), flavonols (e.g., quercetin, kaempferol, myricetin, and fisetin), flavanones (e.g., flavanone, hesperetin, and naringenin), and others. Being phytochemicals, flavonoids cannot be synthesized by humans and animals [28].

They have huge biological potential and promote human health helping to reduce the risk of diseases. Up to date about 9000 flavonoids have been identified [29].

In former studies, we detected significant differences between the inhibitory effects of halogenated $1 \mathrm{H}$-benzimidazole derivatives and flavonoid compounds towards both free catalytic subunits [20,23]. The goal of our present study was to examine if this also holds true for the derived holoenzymes CK $2 \alpha_{2} \beta_{2}$ and CK $2 \alpha^{\prime}{ }_{2} \beta_{2}$. The regulatory subunit CK2 $\beta$ is known to alter the sensitivity of the CK2 molecule towards different substances, like $\mathrm{NaCl}$ and heparin.

\section{Experimental section}

\section{Phytochemicals}

Twenty-one compounds belonging to the various classes of flavonoids were isolated in the pure form from Cirsium rivulare inflorescences, $C$. palustre inflorescences and leaves, and Erigeron acris herb as described before [30-34]. All compounds were obtained from mentioned above plant sources after multistep chromatographic separations of methanolic extracts. The structure and purity of isolated compounds were elucidated on the basis of TLC, spectral analysis in UV and ${ }^{1} \mathrm{H}$ and ${ }^{13} \mathrm{C}$ NMR after comparison with compounds previously obtained in our laboratory, as well as comparison with literature data. Their purity was determined on the level at least $98 \%$. Chrysoeriol was purchased from Roth (Germany).

\section{Purification of human CK2 holoenzymes}

CK $2 \alpha_{2} \beta_{2}$ and CK $2 \alpha_{2}^{\prime} \beta_{2}$ holoenzymes were purified as described elsewhere [35]. Briefly, both catalytic subunits were overexpressed as GST fusion proteins, whereas the regulatory subunit was expressed as His-tagged protein. E. coli BL21(DE3)trxB cells (Novagen) harboring the plasmid pGEX-3X::CSNK2A1, pGEX-3X::CSNK2A2 or pET28a::CSNK2B were grown until $\mathrm{OD}_{600}=0.6$ at $37{ }^{\circ} \mathrm{C}$. Next, IPTG was added to the final concentration of $0.2 \mathrm{mM}$; cultures were continued at room temperature for $4 \mathrm{~h}$ and then centrifuged at $5000 \times g$ for $10 \mathrm{~min}$. Obtained bacterial pellets were mixed prior to lysis. Cells were disrupted by sonication and the supernatant was purified using glutathione-Sepharose (Pharmacia Biotech). Fractions containing the CK2 holoenzyme were pooled and dialysed against $50 \mathrm{mM}$ Tris/HCl buffer $\mathrm{pH} 7.5$ supplemented with $6 \mathrm{mM} \beta$-mercaptoethanol and $30 \%$ glycerol. The obtained protein preparations were used in enzymatic assays.

\section{Substrates}

The protein substrate $\mathrm{P} 2 \mathrm{~B}$ used as phosphate acceptors was overexpressed and purified as previously described [23]. The acidic peptide with the sequence RRRADDSDDDDD was purchased from Sigma-Aldrich.

\section{Protein phosphorylation}

CK2 activity was determined in a standard reaction mixture (40 $\mu \mathrm{L}$ of final volume) containing $20 \mathrm{mM}$ Tris- $\mathrm{HCl}$ buffer, $\mathrm{pH} 7.5,15 \mathrm{mM} \mathrm{MgCl}_{2}, 6 \mathrm{mM} \beta$-mercaptoethanol, and $20 \mu \mathrm{M}$ $\left[\gamma_{-}{ }^{32} \mathrm{P}\right]$ ATP (specific radioactivity $500-1000 \mathrm{cpm} / \mathrm{pmol}$ ) in the presence of $10 \mu \mathrm{M}$ yeast $\mathrm{P} 2 \mathrm{~B}$ as substrate. Incubation was performed at $37{ }^{\circ} \mathrm{C}$ for $15 \mathrm{~min}$. Afterwards, the reaction was terminated by adding $7 \mu \mathrm{L}$ of SDS-PAGE loading buffer. Reaction mixtures were resolved in SDS-PAGE followed by Coomassie blue staining and autoradiography. The phosphate incorporation level in the $\mathrm{P} 2 \mathrm{~B}$ protein was estimated by cutting off the corresponding band and measuring the radioactivity in a scintillation counter (Perkin-Elmer).

Phosphorylation of the peptide substrate $(50 \mu \mathrm{M})$ was terminated by the addition of $10 \%$ orthophosphoric acid, and aliquots were spotted onto phosphocellulose filters (Whatmann P81). Filters were washed with $1 \%$ orthophosphoric acid three times and dried before counting in scintillation counter.

\section{Molecular docking}

CK2 protein structures were modeled and ligand binding studies were carried out using SwissDock (http://www. swissdock.ch/) web service developed by the Molecular Modeling group of the Swiss Institute of Bioinformatics (Lausanne, Switzerland). The modeled and docked structures were analyzed with UCSF Chimera 1.12rc software. The binding site of the structures was identified using the crystal structure of CK2 $\alpha$ (PDB code 1PJK), CK2 $2 \alpha^{\prime}$ (PDB 
code $3 \mathrm{OFM}$ ), and holoenzyme CK $2 \alpha_{2} \beta_{2}$ (1JWH). The docked structures showed binding energy in the range of -7.49 to $-8.48 \mathrm{kcal} / \mathrm{mol}$.

\section{Results and discussion}

In previous studies, we had described the inhibitory effect of different substances like halogenated $1 H$-benzimidazoles and flavonoid compounds towards human catalytic subunits CK2 $\alpha$ and CK2 $\alpha^{\prime}[20,23]$. In our present study, we examined twenty-one flavonoid compounds (Fig. 1) for their potential influence on human protein kinase CK2 holoenzymes. We had already investigated those natural occurring compounds as inhibitors of free CK2 catalytic subunits. The obtained results showed differences between both subunits as well as between the used protein substrates, the acidic ribosomal protein $\mathrm{P} 2 \mathrm{~B}$ and the synthetic peptide RRRADDSDDDDD [23]. Therefore, we were wondering if similar results will be detected using the derived human holoenzymes CK2 $\alpha_{2} \beta_{2}$ and $\mathrm{CK} 2 \alpha_{2}^{\prime} \beta_{2}$. A search in the literature revealed that apigenin (4), luteolin (5), kaempferol (7), and quercetin (8) were already tested on human CK $2 \alpha_{2} \beta_{2}$ and human CK $2 \alpha_{2}^{\prime} \beta_{2}[21$, $22]$. Additionally, we included the compounds from our previous study which showed inhibitory potential towards CK2 catalytic subunits. Both recombinant holoenzymes were obtained by overexpression of CK2 subunits $\alpha, \alpha^{\prime}$, and $\beta$ in $E$. coli, mixing bacteria pellets expressing GST-CK2 $\alpha$ and His-CK $2 \beta$ as well as GST-CK2 $\alpha^{\prime}$ and His-CK2 $\beta$ and purified to homogeneity by affinity chromatography using glutathione-sepharose (GE Healthcare). The inhibitory effect was examined by increasing concentrations of the compound. The experiments were conducted using either P2B or the synthetic peptide as phosphoacceptor. Our obtained results are summarized in Table 1. First, we focused on those compounds exerting the strongest inhibitory effect towards both free catalytic subunits. Chrysoeriol (1), pedalitin (2), apigenin (4), luteolin (5), kaempferol (7), quercetin (8), and cernuoside $(\mathbf{1 0})$ were tested towards both holoenzymes using P2B as substrate. A comparison of chrysoeriol (1) and pedalitin (2) in Fig. 2 illustrates the different potency of both flavonoids towards the free catalytic subunits and their derived holoenzymes. Surprisingly, $\mathrm{IC}_{50}$ values were lower using CK $2 \alpha_{2} \beta_{2}$ than for the CK $2 \alpha^{\prime}{ }_{2} \beta_{2}$ holoenzyme.<smiles>COc1cc(-c2cc(=O)c3c(O)cc(O)cc3o2)ccc1O</smiles><smiles>O=C1/C(=C\c2ccc(O)c(O)c2)Oc2cc(O)cc(O)c21</smiles><smiles>[R]c1cc(O)c2c(=O)cc(-c3ccc(O)cc3)oc2c1</smiles><smiles>[R]c1cc2oc(-c3ccc(O)c(O)c3)cc(=O)c2c(O)c1[R]</smiles>

$4 \quad \mathrm{R}=\mathrm{OH}$

4a $\quad \mathrm{R}=O$-glucosyl

4b $\quad \mathrm{R}=O$-glucuronyl

4c $\quad \mathrm{R}=O$-methylglucuronyl<smiles>[R]c1c(-c2ccc(O)cc2)oc2cc(O)cc(O)c2c1=O</smiles>

$7 \quad \mathbf{R}=\mathbf{O H}$

7a $\quad \mathrm{R}=\boldsymbol{O}$-glucosyl

$$
\begin{aligned}
5 R^{1} & =H, R^{2}=O H \\
5 a R^{1} & =H, R^{2}=O \text {-glucosyl } \\
5 b R^{1} & =O H, R^{2}=O \text {-glucosyl }
\end{aligned}
$$<smiles>[R]c1c(-c2ccc(O)c(O)c2)oc2cc(O)cc(O)c2c1=O</smiles>

8

8a $\quad \mathbf{R}=O$-glucosyl<smiles>[R]c1cc(O)c2c(=O)c(OC)c(-c3ccc(O)cc3)oc2c1</smiles>

$6 \quad \mathrm{R}=\mathrm{OH}$

6a $\quad \mathrm{R}=O$-glucosyl

6b $\quad \mathrm{R}=O$-glucuronyl

6c $\quad \mathrm{R}=O$-methylglucuronyl<smiles>[R]c1cc2oc(-c3ccc(O)cc3)cc(=O)c2c(O)c1O</smiles>

$9 \quad \mathrm{R}=O$-glucuronyl

9a $\quad \mathrm{R}=O$-glucosyl

Fig. 1 Structures of flavonoids tested in this study 
Table $1 \mathrm{IC}_{50}$ values $(\mu \mathrm{M})$ of the tested compounds

\begin{tabular}{|c|c|c|c|c|c|c|c|c|}
\hline \multirow[t]{2}{*}{ Inhibitor } & \multicolumn{4}{|l|}{ P2B } & \multicolumn{4}{|c|}{ Synthetic peptide } \\
\hline & $\mathrm{CK} 2 \alpha^{(\mathrm{a})}$ & $\mathrm{CK} 2 \alpha^{\prime(\mathrm{a})}$ & $\mathrm{CK} 2 \alpha_{2} \beta_{2}$ & $\mathrm{CK} 2 \alpha_{2}^{\prime} \beta_{2}$ & $\mathrm{CK} 2 \alpha^{(\mathrm{a})}$ & $\mathrm{CK} 2 \alpha^{\prime(\mathrm{a})}$ & $\mathrm{CK} 2 \alpha_{2} \beta_{2}$ & $\mathrm{CK} 2 \alpha_{2}^{\prime}{ }_{2} \beta_{2}$ \\
\hline 1 & $0.42 \pm 0.09$ & $0.06 \pm 0.01$ & $0.06 \pm 0.001$ & $0.1 \pm 0.008$ & $0.25 \pm 0.02$ & $0.03 \pm 0.007$ & $0.08 \pm 0.004$ & $0.08 \pm 0.07$ \\
\hline 2 & $7.0 \pm 0.5$ & $0.4 \pm 0.05$ & $0.2 \pm 0.03$ & $0.35 \pm 0.03$ & $0.4 \pm 0.02$ & $0.2 \pm 0.03$ & $0.2 \pm 0.01$ & $0.25 \pm 0.05$ \\
\hline 3 & $21 \pm 1.8$ & $3.3 \pm 0.5$ & $1.55 \pm 0.1$ & $1.2 \pm 0.1$ & $11.2 \pm 0.9$ & $4.7 \pm 0.4$ & $7.2 \pm 0.5$ & $3.8 \pm 0.4$ \\
\hline 4 & $9.8 \pm 0.8$ & $2.3 \pm 0.1$ & $1.5 \pm 0.1$ & $2.5 \pm 0.2$ & $3.9 \pm 0.3$ & $1.5 \pm 0.2$ & $0.8 \pm 0.03$ & $2.4 \pm 0.2$ \\
\hline $4 \mathbf{a}$ & $>40$ & $12.5 \pm 0.9$ & $11.2 \pm 0.5$ & $15.7 \pm 1.2$ & $>40$ & $>40$ & $12.1 \pm 0.9$ & $13.2 \pm 1.1$ \\
\hline $4 b$ & $16.6 \pm 1.4$ & $0.4 \pm 0.06$ & $12.4 \pm 0.6$ & $16.5 \pm 1.2$ & $3.6 \pm 0.2$ & $5.4 \pm 0.4$ & $9.4 \pm 0.6$ & $22.8 \pm 1.4$ \\
\hline $4 c$ & $>40$ & $3.3 \pm 0.4$ & $14.2 \pm 0.6$ & $12.5 \pm 0.9$ & $14.3 \pm 0.8$ & $24 \pm 2.5$ & $10.5 \pm 0.8$ & $5.6 \pm 0.3$ \\
\hline 5 & $6.0 \pm 0.7$ & $1.0 \pm 0.1$ & $0.55 \pm 0.07$ & $0.65 \pm 0.05$ & $2.0 \pm 0.1$ & $0.75 \pm 0.1$ & $0.5 \pm 0.02$ & $1.0 \pm 0.07$ \\
\hline $5 \mathbf{a}$ & $17.5 \pm 1.5$ & $0.8 \pm 0.1$ & $31.0 \pm 2.3$ & $9.5 \pm 0.7$ & $0.1 \pm 0.03$ & $0.7 \pm 0.1$ & $9.0 \pm 0.5$ & $5.7 \pm 0.06$ \\
\hline $5 \mathbf{b}$ & $5.8 \pm 0.5$ & $0.35 \pm 0.07$ & $>40$ & $3.2 \pm 0.4$ & $7.0 \pm 0.4$ & $0.4 \pm 0.05$ & $6.2 \pm 0.3$ & $3.6 \pm 0.04$ \\
\hline 6 & $>40$ & $13.6 \pm 0.9$ & $17.5 \pm 1.4$ & $12.1 \pm 1.1$ & $11.2 \pm 0.9$ & $13.7 \pm 1.1$ & $7.7 \pm 0.4$ & $10.2 \pm 0.7$ \\
\hline $6 \mathbf{a}$ & $>40$ & $>40$ & $>40$ & $>40$ & $>40$ & $>40$ & $>40$ & $>40$ \\
\hline $6 b$ & $>40$ & $3.0 \pm 0.2$ & $9.9 \pm 0.8$ & $3.5 \pm 0.1$ & $>40$ & $7.7 \pm 0.8$ & $5.0 \pm 0.2$ & $5.3 \pm 0.3$ \\
\hline $6 c$ & $>40$ & $>40$ & $>40$ & $>40$ & $17 \pm 1.8$ & $>40$ & $>40$ & $>40$ \\
\hline 7 & $4.8 \pm 0.4$ & $1.0 \pm 0.05$ & $0.35 \pm 0.04$ & $0.35 \pm 0.02$ & $0.7 \pm 0.1$ & $0.2 \pm 0.02$ & $0.3 \pm 0.02$ & $0.3 \pm 0.04$ \\
\hline $7 \mathbf{a}$ & $>40$ & $>40$ & $>40$ & $>40$ & $>40$ & $>40$ & $>40$ & $>40$ \\
\hline 8 & $1.8 \pm 0.2$ & $0.2 \pm 0.007$ & $0.25 \pm 0.03$ & $0.25 \pm 0.02$ & $0.5 \pm 0.05$ & $0.4 \pm 0.03$ & $0.5 \pm 0.03$ & $1.0 \pm 0.08$ \\
\hline $8 \mathbf{a}$ & $>40$ & $19.2 \pm 1.5$ & $24.5 \pm 1.7$ & $31.9 \pm 2.6$ & $3.7 \pm 0.4$ & $>40$ & $>40$ & $>40$ \\
\hline 9 & $33 \pm 2.8$ & $4.3 \pm 0.3$ & $>40$ & $>40$ & $>40$ & $4.1 \pm 0.5$ & $19.1 \pm 1.7$ & $9.7 \pm 0.8$ \\
\hline $9 a$ & $>40$ & $3.8 \pm 0.2$ & $0.4 \pm 0.06$ & $6.3 \pm 0.5$ & $3.0 \pm 0.4$ & $4.4 \pm 0.5$ & $5.4 \pm 0.3$ & $3.2 \pm 0.2$ \\
\hline 10 & $5.8 \pm 0.4$ & $5.1 \pm 0.3$ & $3.7 \pm 0.3$ & $7.8 \pm 0.7$ & $5.3 \pm 0.5$ & $4.0 \pm 0.3$ & $5.1 \pm 0.3$ & $9.6 \pm 0.8$ \\
\hline
\end{tabular}

Experiments were performed using yeast ribosomal protein P2B or synthetic peptide as substrate and in the presence of $20 \mu \mathrm{M}$ ATP The results represent the means of three independent experiments

${ }^{(a)}$ Data from ref. [23]

Fig. 2 Inhibition of different CK2 isoforms. Comparison of chrysoeriol (a) and pedalitin (b) and their influence on CK2 $\alpha$ (black circle), $\mathrm{CK} 2 \alpha^{\prime}$ (black square), CK $2 \alpha_{2} \beta_{2}$ (white circle), and CK $2 \alpha_{2}^{\prime} \beta_{2}$ (white square) phosphorylating activity. The experiment was carried out using $10 \mu \mathrm{M}$ P2B as protein substrate and $20 \mu \mathrm{M}$ ATP as phospho-donor. The results are the means of three independent experiments
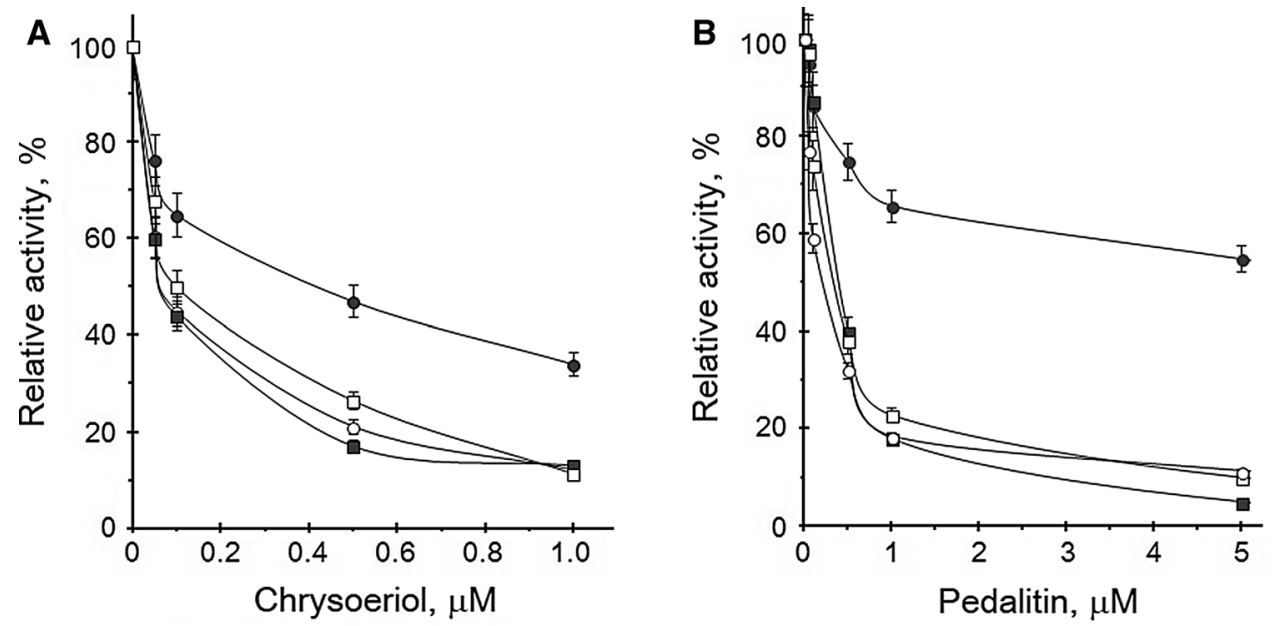

In case of free catalytic subunits, the inhibitory effect was almost always stronger towards the CK2 $\alpha^{\prime}$ subunit. Comparing the inhibition of the free $\mathrm{CK} 2 \alpha^{\prime}$ subunit with $\mathrm{IC}_{50}$ values from 0.06 to $5.1 \mu \mathrm{M}$ for chrysoeriol and cernuoside, respectively, with its holoenzyme $(0.1-7.8 \mu \mathrm{M})$, the $\mathrm{IC}_{50}$ values were similar or higher for the holoenzyme. The difference between $\mathrm{CK} 2 \alpha$ and the holoenzyme was significant, with
$\mathrm{IC}_{50}$ values testing the free catalytic subunit of $0.42 \mu \mathrm{M}$ for chrysoeriol and $9.8 \mu \mathrm{M}$ for apigenin, but $0.06 \mu \mathrm{M}$ for chrysoeriol and $1.5 \mu \mathrm{M}$ for apigenin in case of the holoenzyme. Most potent inhibitor as in case for the free catalytic subunits is chrysoeriol (1) inhibiting all four molecular forms of $\mathrm{CK} 2$ with $\mathrm{IC}_{50}$ values below $0.42 \mu \mathrm{M}$. Interestingly, luteolin derivatives $(\mathbf{5 a}, \mathbf{b})$ revealed opposite effect on CK2 than 
the parent compound. Whereas the inhibition is stronger comparing the holoenzyme and the respective free catalytic subunit ( 6.0 vs. $0.55 \mu \mathrm{M}$ for CK $2 \alpha$ and holoenzyme) in the presence of luteolin (5), both derivatives possess similar or even weaker activities towards the holoenzymes. Also, the strong inhibitory potential was lost in case of both luteolin derivatives $(\mathbf{5 a}, \mathbf{b})$ on the $\mathrm{CK} 2 \alpha^{\prime}{ }_{2} \beta_{2}$ holoenzyme compared to luteolin (5) which was not the case for the free catalytic subunits. This decrease was even much stronger for the CK2 $\alpha^{\prime}{ }_{2} \beta_{2}$ holoenzyme with $\mathrm{IC}_{50}$ values about tenfold higher. Pedalitin (2), tricin (3), luteolin (5), kaempferol (7) are the only compounds inhibiting both holoenzymes better than the respective free catalytic subunits. Within the tested compounds, we found examples where inhibition of the holoenzyme was detected even in case where no effect was seen for the free catalytic subunit. Isokaempferide (6) influenced the CK2 activity of both holoenzymes with $\mathrm{IC}_{50}$ values of 17.5 and $12.1 \mu \mathrm{M}$. Its derivatives $(\mathbf{6 a}-\mathbf{c})$ showed different effects with $\mathrm{IC}_{50}$ of 9.9 and $3.5 \mu \mathrm{M}$ (compound $\mathbf{6 b}$ ) or without any inhibition (compounds $\mathbf{6 a}, \mathbf{c}$ ). Otherwise, the same derivatives of apigenin (4), namely the 7-O-glucoside (4a), 7-O-glucuronide (4b), and 7-O-methylglucuronide (4c) inhibited with a similar extent $\left(\mathrm{IC}_{50}\right.$ values between 11.2 and $16.5 \mu \mathrm{M}$ ) both holoenzymes but much less effective than the parent compound apigenin (4) inhibiting the CK2 activities to $50 \%$ at 1.5 and $2.5 \mu \mathrm{M}$.

The glucosylation at position C-3 or C-7 dramatically lowered the inhibitory potency in case of derivatives of apigenin (4a), luteolin (5a), isokaempferide (6a), kaempferol (7a), and quercetin (8a). The decrease in the potential of these compounds lies between sixfold up to over 100-fold for apigenin 7-O-glucoside and quercetin 3-O-glucoside, respectively. Noteworthy compounds $\mathbf{6 a}$ and $7 \mathbf{a}$ did not show any effect on the CK2 activities.

Scutellarin (9) was shown to exhibit very weak potential towards CK $2 \alpha$ but good inhibition in case of CK $2 \alpha^{\prime}$. Similar effect was detected for scutellarein 7-O-glucoside (9a) which completely failed in case of CK $2 \alpha$. Interestingly, compound 9a possesses very good inhibitory potential towards CK $2 \alpha_{2} \beta_{2}$ with an $\mathrm{IC}_{50}$ of $0.4 \mu \mathrm{M}$, but weaker potential towards CK $2 \alpha^{\prime}{ }_{2} \beta_{2}$ than on CK2 $\alpha^{\prime}$ (Table 1 ).

In most publications instead of a full protein substrate, like $\mathrm{P} 2 \mathrm{~B}$, a synthetic peptide is used as phosphoacceptor containing the typical recognition site for protein kinase CK2. In most cases, CK $2 \alpha_{2} \beta_{2}$ was better inhibited than CK $2 \alpha$. As illustrated in Fig. 3 comparing flavonoid compounds towards the their influences on different CK2 isoforms revealed diverse results. Whereas mainly CK2 $\alpha$ is less inhibited than CK2 $\alpha^{\prime}$ in case of luteolin derivative 5a the opposite is the fact. Similar behavior was detected comparing the $\mathrm{IC}_{50}$ values of CK $2 \alpha$ and CK $2 \alpha_{2} \beta_{2}$. In most cases, the holoenzyme was stronger inhibited than the free catalytic subunit, but compound 5a is one of the few exceptions.

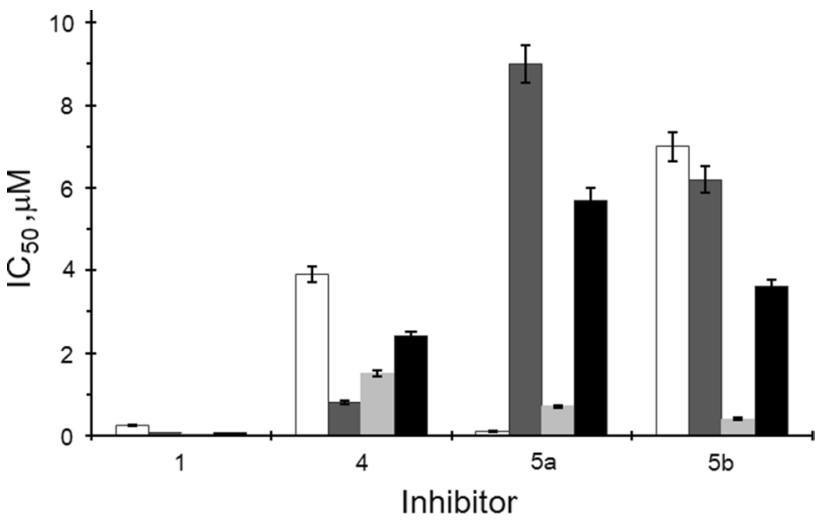

Fig. 3 Comparison of compounds chrysoeriol (1), apigenin (4), luteolin 7-O-glucoside (5a), and 6-hydroxyluteolin 7-O-glucoside (5b) towards their inhibitory potential on CK2 $\alpha$ (white), CK2 $\alpha_{2} \beta_{2}$ (dark gray), CK $2 \alpha^{\prime}$ (light grey), and CK $2 \alpha_{2}^{\prime} \beta_{2}$ (black) phosphorylation. The experiments were carried out in the presence of $50 \mu \mathrm{M}$ of the synthetic peptide and in the presence of $20 \mu \mathrm{M}$ ATP. The results are the means of three independent experiments

In general, the CK2 $\alpha^{\prime}$ subunit is more sensible towards the tested flavonoid compounds than the derived holoenzyme. Quercetin (8) and cernuoside (10) possess similar inhibitory potential towards CK2 $\alpha$ and its holoenzyme. Apigenin 7-O-glucuronide (4b) and luteolin 7- $O$-glucoside (5a) were less active on CK $2 \alpha_{2} \beta_{2}$ than towards CK2 $\alpha$ but still had a moderate inhibitory effect with $\mathrm{IC}_{50}$ values of 9.4 and $9.0 \mu \mathrm{M}$. The $O$-glucoside derivatives of isokaempferide (6a), kaempferol (7a), and quercetin (8a) as well as isokaempferide 7-O-methylglucuronide (6c) were completely ineffective towards both holoenzymes similar like towards the free catalytic subunit with exception of $\mathbf{6 c}$ and quercetin 3-O-glucoside (8a) with $\mathrm{IC}_{50}$ values of 17 and $3.7 \mu \mathrm{M}$ towards CK2 $\alpha$, respectively (Table 1). Surprisingly, apigenin 7-O-glucoside (4a) showed similar inhibitory effect towards both holoenzymes, whereas it was inactive on free catalytic subunits. There are several compounds inhibiting CK2 $2 \alpha^{\prime}$ and its holoenzyme in the same range, like pedalitin (2), tricin (3), apigenin (4), luteolin (5), isokaempferide (6), kaempferol (7). Other compounds, like chrysoeriol (1), quercetin (8), scutellarin (9), and cernuoside (10) showed a 2.5-fold stronger influence on CK2 $\alpha^{\prime}$ than on the derived holoenzyme (Table 1).

As already described by others $[19,22]$ and in our former work [23] flavonoids are strictly ATP-competitive inhibitors. Therefore, Lolli et al. tested some flavonoid compounds and their inhibitory efficiency against two CK2 $\alpha$ mutants, Val66Ala and Ile174Ala [22]. Interestingly, the $\mathrm{IC}_{50}$ values of quercetin, luteolin, and apigenin were only marginally affected by both mutations. Therefore, we were interested to investigate the binding mode of three inhibitors, namely, chrysoeriol (1), apigenin (4), and quercetin $(\mathbf{8})$ with the three available CK2 isoform 

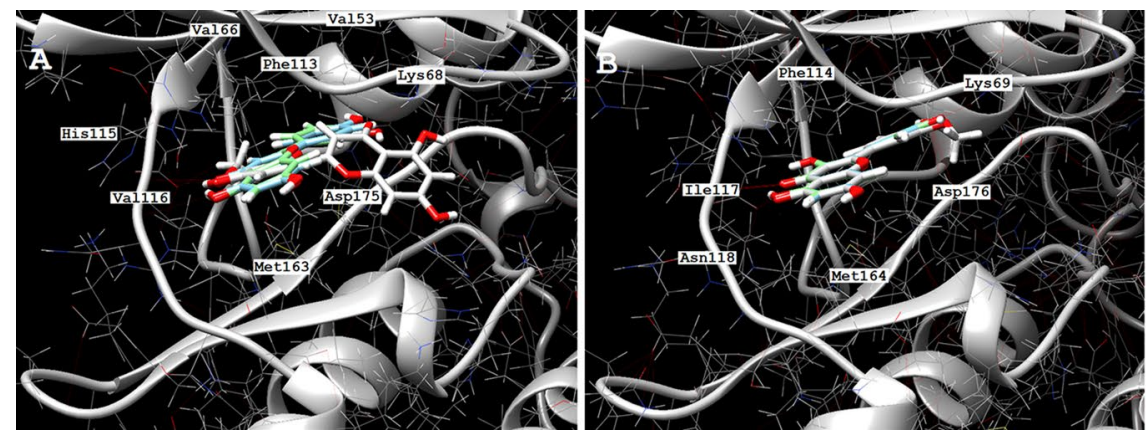

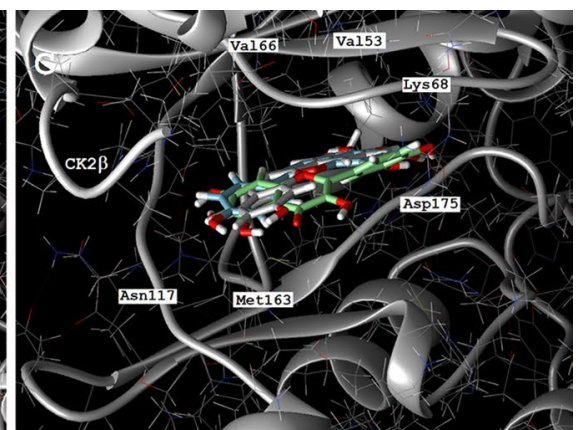

Fig. 4 Comparison of the binding modes of chrysoeriol (white), apigenin (blue), and quercetin (green) to CK2 $\alpha$ (a), CK2 $2 \alpha^{\prime}$ (b), and CK $2 \alpha_{2} \beta_{2}$ (c) obtained with molecular docking. The docking was pro- vided using the Swissdock web server and analysis was done with UCSF Chimera 1.12rc software. (Color figure online) structures (Fig. 4). The three compounds differs in their amount of hydroxyl groups and in case of chrysoeriol a methoxyl group at position $3^{\prime}$. Apigenin and quercetin, the latter possesses two additional hydroxyl groups at position 3 and $3^{\prime}$ compared to apigenin, bind in a similar manner to each CK2 isoform. A remarkable difference was seen when chrysoeriol was docked to the CK $2 \alpha$ structure. As shown in Fig. 4a chrysoeriol binds in a $90^{\circ}$ angle compared to the other both inhibitors to the ATP-binding site of the enzyme. By this way, the pocket is more blocked by chrysoeriol which could be the reason for its higher inhibitory potential. Also noteworthy is the slightly different position of chrysoeriol bound to the CK $2 \alpha$ holoenzyme. Anyway, there is almost no difference detectable in the distance between inhibitor and amino acid chains ranging between 2.2 and $2.4 \AA$. Comparing the binding energy, we observed lower energy in case of the CK2 $\alpha^{\prime} /$ chrysoeriol complex than chrysoeriol complexed with $\mathrm{CK} 2 \alpha$ and its holoenzyme. This is consistent with the results from the enzymatic studies where the inhibition is stronger for CK2 $\alpha^{\prime}$. The interaction between flavonoids and CK2 isoforms is mainly due to the formation of H-bonds with Lys68 (Lys69 in case of CK2 $\alpha^{\prime}$ ), Val116 (Ile117 in case of CK2 $\alpha^{\prime}$ ), and Asp175 (Asp176 in case of CK2 $\alpha^{\prime}$ ).

The CK2 holoenzymes differ in their biochemical characteristics which could be the reason for various sensitivity towards inhibitors. The study of Olsen et al. described the similarities and differences between the CK2 $\alpha$ - and CK $2 \alpha^{\prime}$-derived holoenzymes [36]. Interestingly, the CK $2 \alpha_{2} \beta_{2}$ holoenzyme is more stable at $45{ }^{\circ} \mathrm{C}$ due to the increase of the $\alpha$-helical character of the subunits. Analysis by gel filtration revealed that the $\mathrm{CK} 2 \alpha^{\prime}{ }_{2} \beta_{2}$ holoenzyme exists only as protomer, whereas the $\mathrm{CK} 2 \alpha_{2} \beta_{2}$ holoenzyme is able to aggregate to higher molecular mass forms. In a later publication, the same research groups showed that CK $2 \alpha^{\prime}$ is able to form a trimer $\left(\mathrm{CK} 2 \alpha^{\prime} \beta_{2}\right)$ instead of the typical tetrameric form [37].

\section{Conclusions}

Protein kinase $\mathrm{CK} 2$ exists as several isoforms, namely CK $2 \alpha$, CK $2 \alpha^{\prime}$, CK $2 \alpha_{2} \beta_{2}$, CK $2 \alpha^{\prime}{ }_{2} \beta_{2}$, whereas, the holoenzyme is the predominantly occurring form in the cell.

As reported in several publications, the CK2 $\beta$ subunit regulates the preference for the protein substrate and possesses influence towards the structure of the ATP/ GTP-binding site $[11,38,39]$. These interactions might be responsible for the different potential of the tested flavonoids in this work since flavonoids are pure ATPcompetitive. To resolve this question, the crystal structure of bound inhibitor to the free catalytic subunit and the holoenzyme has to be done. Unfortunately, up to now, there is no crystal structure available for the $\mathrm{CK} 2 \alpha^{\prime}{ }_{2} \beta_{2}$ holoenzyme.

Flavonoids are promising compounds in the search for new CK2 inhibitors and in further future as potential anti-cancer drugs. There are numerous reports about their cytotoxic effect on cancer cell lines in vitro or chemopreventive possibilities as components of daily diet [40].

Funding This research did not receive any specific grant from funding agencies in the public, commercial, or not-for-profit sectors.

\section{Compliance with ethical standards}

Conflict of interest The authors declare that they have no conflict of interest.

Open Access This article is distributed under the terms of the Creative Commons Attribution 4.0 International License (http://creativecommons.org/licenses/by/4.0/), which permits unrestricted use, distribution, and reproduction in any medium, provided you give appropriate credit to the original author(s) and the source, provide a link to the Creative Commons license, and indicate if changes were made. 


\section{References}

1. Pinna LA, Meggio F (1997) Protein kinase CK2 ("casein kinase-2") and its implication in cell division and proliferation. Prog Cell Cycle Res 3:77-97

2. Ahmed K, Davis AT, Wang H, Faust RA, Yu S, Tawfic S (2000) Significance of protein kinase CK2 nuclear signaling in neoplasia. J Cell Biochem 79:130-135

3. Litchfield DW (2003) Protein kinase CK2: structure, regulation and role in cellular decisions of life and death. Biochem J 369:1-15

4. Ahmad KA, Wang G, Unger G, Slaton J, Ahmed K (2008) Protein kinase CK2 - a key suppressor of apoptosis. Adv Enzyme Regul 48:179-187

5. Ahmed K, Gerber D, Cochet C (2002) Joining the cell survival squad: an emerging role for protein kinase CK2. Trends Cell Biol $12: 226-230$

6. Canton DA, Litchfield DW (2006) The shape of things to come: an emerging role for protein kinase CK2 in the regulation of cell morphology and the cytoskeleton. Cell Signal 18:267-275

7. Filhol O, Deshiere A, Cochet C (2013) In: Pinna LA (ed) Protein kinase CK2, Wiley, Oxford, pp 363-381

8. Kramerov AA, Saghizadeh M, Caballero S, Shaw LC, Li Calzi S, Bretner M, Montenarh M, Pinna LA, Grant MB, Ljubimov AV (2008) Inhibition of protein kinase CK2 suppresses angiogenesis and hematopoietic stem cell recruitment to retinal neovascularization sites. Mol Cell Biochem 316:177-186

9. Montenarh M (2014) Protein kinase CK2 and angiogenesis. Adv Clin Exp Med 23:153-158

10. Guerra B, Issinger OG (2008) Protein kinase CK2 in human diseases. Curr Med Chem 15:1870-1886

11. Bibby AC, Litchfield DW (2005) The multiple personalities of the regulatory subunit of protein kinase CK2: CK2 dependent and CK2 independent roles reveal a secret identity for CK2 $\beta$. Int J Biol Sci 1:67-79

12. Bidwai AP, Reed JC, Glover CVC (1993) Phosphorylation of calmodulin by thecatalytic subunit of casein kinase II is inhibited by the regulatory subunit. Arch Biochem Biophys 300:265-270

13. Poletto G, Vilardell J, Marin O, Pagano MA, Cozza G, Sarno S, Falqués A, Itarte E, Pinna LA, Meggio F (2008) The regulatory $\beta$ subunit of protein kinase CK2contributes to the recognition of the substrate consensus sequence. A study with an eIF2 $\beta$-derived peptide. Biochemistry 47:8317-8325

14. Hanks SK, Quinn AM (1991) Protein kinase catalytic domain sequence database: identification of conserved features of primary structure and classification of family members. Methods Enzymol 200:38-62

15. Allende JE, Allende CC (1995) Protein kinase CK2: an enzyme with multiple substrates and a puzzling regulation. FASEB J 9:313-323

16. Guerra B, Siemer S, Boldyreff B, Issinger OG (1999) Protein kinase CK2: evidence for a protein kinase CK2 $\beta$ subunit fraction, devoid of the catalytic CK2 $\alpha$ subunit, in mouse brain and testicles. FEBS Lett 462:353-357

17. Landesman-Bollag E, Belkina A, Hovey B, Connors E, Cox C, Seldin DC (2011) Developmental and growth defects in mice with combined deficiency of CK2 catalytic genes. Mol Cell Biochem 356:227-231

18. Battistutta R (2009) Structural basis of protein kinase CK2 inhibition. Cell Mol Life Sci 66:1868-1889

19. Golub AG, Bdzhola VG, Kyshenia YV, Sapelkin VM, Prykhod'ko AO, Kukharenko OP, Ostrynska OV, Yarmoluk SM (2011) Structure-based discovery of novel flavonol inhibitors of human protein kinase CK2. Mol Cell Biochem 356:107-115

20. Janeczko M, Orzeszko A, Kazimierczuk Z, Szyszka R, Baier A (2012) CK2 $\alpha$ and CK2 $\alpha^{\prime}$ subunits differ in their sensitivity to 4,5,6,7-tetrabromo- and 4,5,6,7-tetraiodo- $1 \mathrm{H}$-benzimidazole derivatives. Eur J Med Chem 47:345-350

21. Li C, Liu X, Lin X, Chen X (2009) Structure-activity relationship of 7 flavonoids on recombinant human protein kinase CK2 holoenzyme. J Cent South Univ (Med Sci) 34:20-27

22. Lolli G, Cozza G, Mazzorana M, Tibaldi E, Cesaro L, DonellaDeana A, Meggio F, Venerando A, Franchin C, Sarno S, Battistutta R, Pinna LA (2012) Inhibition of protein kinase CK2 by flavonoids and tyrphostins. A structural insight. Biochemistry 51:6097-6107

23. Baier A, Galicka A, Nazaruk J, Szyszka R (2017) Selected flavonoid compounds as promising inhibitors of protein kinase CK2 $\alpha$ and CK2 $\alpha^{\prime}$, the catalytic subunits of CK2. Phytochemistry 136:39-45

24. Syniugin AR, Ostrynska OV, Chekanov MO, Volynets GP, Starosyla SA, Bdzhola VG, Yarmoluk SM (2016) Design, synthesis and evaluation of 3-quinoline carboxylic acids as new inhibitors of protein kinase CK2. J Enzyme Inhib Med Chem 31:160-169

25. Hundsdörfer C, Hemmerling HJ, Götz C, Totzke F, Bednarski P, Le Borgne M, Jose J (2012) Indeno[1,2-b]indole derivatives as a novel class of potent human protein kinase CK2 inibitors. Bioorg Med Chem 20:2282-2289

26. Pourmorad F, Hosseinimehr SJ, Shahabimajd N (2006) Antioxidant activity, phenol and flavonoid contents of some selected Iranian medicinal plants. Afr J Biotechnol 5:1142-1145

27. Kumar S, Pandey AK (2012) Antioxidant, lipo-protective and antibacterial activities of phytoconstituents present in Solanum xanthocarpum root. Intern Rev Biophys Chem 3:42-47

28. Koes R, Verweij W, Quattrocchio F (2005) Flavonoids: a colourful model for the regulation and evolution of biochemical pathways. Trends Plant Sci 10:236-242

29. Ferrer J, Austin M, Stewart CJ, Noel J (2008) Structure and function of enzymes involved in the biosynthesis of phenylpropanoids. Plant Physiol Biochem 46:356-370

30. Nazaruk J (2006) Flavonoid aglycones and phytosterols from the Erigeron acris L. herb. Acta Pol Pharm Drug Res 63:317-319

31. Nazaruk J (2009) Flavonoid compounds from Cirsium palustre (L.) Scop. flower heads. Biochem Systemat Ecol 37:525-527

32. Nazaruk J, Galicka A (2014) The influence of selected flavonoids from leaves of Cirsium palustre (L.) Scop. on collagen expression in human skin fibroblasts. Phytother Res 28:1399-1405

33. Nazaruk J, Jakoniuk P (2005) Flavonoid composition and antimicrobial activity of Cirsium rivulare (Jacq.) All. flowers. J Ethnopharmacol 102:208-212

34. Nalewajko-Sieliwoniuk E, Nazaruk J, Antypiuk E, Kojło A (2008) Determination of phenolic compounds and their antioxidant activity in Erigeron acris L. extracts and pharmaceutical formulation by flow injection analysis with inhibited chemiluminescent detection. J Pharmaceut Biomed Anal 48:579-586

35. Turowec JP, Duncan JS, French AC, Gyenis L, St.-Denis NA, Vilk G, Litchfield DW (2010) Protein kinase CK2 is a constitutively active enzyme that promotes cell survival: strategies to identify CK2 substrates and manipulate its activity in mammalian cells. Methods Enzymol 484:471-493

36. Olsen BB, Boldyreff B, Niefind K, Issinger OG (2006) Purification and characterization of the CK2alpha'-based holoenzyme, an isozyme of CK2alpha: a comparative analysis. Protein Expr Purif 47:651-661

37. Olsen BB, Rasmussen T, Niefind K, Issinger OG (2008) Biochemical characterization of CK2alpha and alpha' paralogues and their derived holoenzymes: evidence for the existence of a heterotrimeric CK2alpha'-holoenzyme forming trimeric complexes. Mol Cell Biochem 316:37-47

38. Janeczko M, Masłyk M, Szyszka R, Baier A (2011) Interactions between subunits of protein kinase CK2 and their protein substrates influences its sensitivity to specific inhibitors. Mol Cell Biochem 356:121-126 
39. Kubiński K, Domańska K, Sajnaga E, Mazur E, Zieliński R, Szyszka $R$ (2007) Yeast holoenzyme of protein kinase CK2 requires both beta and beta' regulatory subunits for its activity. Mol Cell Biochem 295:229-236
40. Batra P, Sharma AK (2013) Anti-cancer potential of flavonoids: recent trends and future perspectives. 3 Biotech 3:439-459 